\title{
CLINICAL VALUE OF THYMIDINE KINASE AND TISSUE POLYPEPTIDE SPECIFIC ANTIGEN IN BREAST CANCER
}

\author{
O. MANSOUR, T. MOTAWI*, H. KHALED**, O. EL-AHMADY \\ Tumour Marker Oncology Research Center, Al-Azhar University. \\ *Biochemistry Dept., Faculty of Pharmacy, Cairo University. \\ **Medical Oncology Dept., National Cancer Institute, Cairo, Egypt.
}

\begin{abstract}
SUMMARY
Thymidine kinase (TK) and tissue polypeptide specific antigen (TPS) were determined in breast cancer $(B C)$ patients $(n=83)$, normal healthy women $(n=30)$ and 18 women with different benign mastopathies. Mean serum levels of TK and TPS in BC patients showed significant increases from their corresponding levels in healthy women and those with benign breast diseases. Diagnostic sensitivity of TK and TPS was $47 \%$ and $58 \%$ respectively at the selected cut-off values $8 \mathrm{U} / \mathrm{L}$ for TK and $110 \mathrm{U} / \mathrm{L}$ for TPS (96\% specificity).

Pre-operative serum levels of TK and TPS showed significant correlation with the stage of disease and with other classical prognostic factors; clinical stage, tumour size, lymph node involvement and distant metastasis.

Nineteen BC patients were followed-up by serial monthly measurements of TK and TPS (4-10 samples). Both markers seemed to be valuable in monitoring drug efficacy. TK and TPS were able to detect systemic recurrence before clinical diagnosis (average 2 months lead time). TPS was greatly affected by liver diseases.
\end{abstract}

KEY WORDS Thymidine Kinase TPS Breast Cancer

\section{INTRODUCTION}

Thymidine kinase is a cellular enzyme which is involved in the salvage pathway of DNA synthesis. It is activated in the G1/S phase of the cell cycle (Bello, 1974), and its activity has been shown to correlate with proliferative activity of the tumour cells (Gronowitz et al., 1984). Clinical studies have reported elevated serum TK level in hematological tumours (Hagberg et al., 1984) and solid tumours such as prostatic, breast and small cell lung cancers (Hallek et al., 1992).

Tissue polypeptide specific antigen (TPS) was developed to react specifically with the $\mathrm{M}_{3}$ essential epitope of tissue polypeptide antigen (TPA). It is synthesized during the late $\mathrm{S}$ - and $\mathrm{G} 2$ phases of the cell cycle and released immediately after mitosis (Bjorklund and Bjorklund, 1983). It was reported that TPS is closely related to cell proliferation as demonstrated by DNA synthesis and cell viability studies (Madersbacher et al., 1992). However, some authors have demonstrated that TPS is one of the normal basic keratins in the cell and suggest that it has nothing to do with the proliferation rate of the malignant cells (Oehr, 1992). Apart from these conflicting concepts, some clinical investigations

Correspondence to: Omar El-Ahmady, Head of Tumor Marker Oncology Research Center, 2 Roshdy st., Safeer Square, Heliopolis, Cairo, Egypt. 
have established the usefulness of TPA and TPS as markers for the proliferative activity of cancer cells (Van Dalen, 1992; Bremer et al., 1992).

\section{MATERIALS AND METHODS}

The present work included 83 women with primary breast cancer (operable $n=75$ and inoperable $n=8$ ), attending the National Cancer Institute. They were categorized as follows:

\begin{tabular}{|c|c|c|c|c|c|c|c|c|c|c|c|c|c|c|c|}
\hline \multirow{2}{*}{$\begin{array}{c}\text { Category } \\
\text { and }\end{array}$} & \multicolumn{2}{|c|}{ Menopause } & \multicolumn{4}{|c|}{ Clinical stage } & \multicolumn{2}{|c|}{$\begin{array}{c}\text { Tumor size } \\
\mathrm{Cm} .\end{array}$} & \multicolumn{2}{|c|}{$\begin{array}{c}\text { Axillary } \\
\text { Lymph node }\end{array}$} & \multicolumn{3}{|c|}{$\begin{array}{l}\text { Histological } \\
\text { Type }\end{array}$} & \multicolumn{2}{|c|}{$\begin{array}{c}\text { Histological } \\
\text { Grade }\end{array}$} \\
\hline & Pre. & Post & I & II & III & IV & $\leq 2>2-<4$ & $\geq 4$ & $\mathrm{~N}-$ & $\mathrm{N}+$ & IDC & LC & M & I & III \\
\hline No. & 38 & 45 & 4 & 29 & 42 & 8 & 20 & 40 & 17 & 58 & 65 & 7 & 3 & 11 & 35 \\
\hline
\end{tabular}

Preoperative serum samples were withdrawn from them. Nineteen patients were followed-up during hormonal and/or cytostatic chemotherapy by monthly measurement of serum TK, TPS and routine clinical investigation. Samples were taken before each cytostatic dose, Sonography and/or bone scan were done to identify the metastatic deposits. Serum samples were also withdrawn from 18 women with different benign mastopathies and from 30 age-matched normal healthy women as reference controls.

Serum TK was determined by radioenzyme assay reagents, supplied by Sangtec Medical Bromma, Sweden. Sample was added to ${ }^{125}$ I labeled substrate, incubated for 4 hours, reaction stopped and phosphorylated reaction product separated. The radioactivity of the separated product as measured is directly proportional to the enzyme in the original sample. Serum TPS was assayed using immunoassay reagents, supplied by BEKI Diagnostics AB, Bromma, Sweden. TPA in the sample was allowed to react with peroxidase-conjugated anti-TPA antibodies (monoclonal) and anti-TPA antibodies (polyclonal) bound to plastic bead. Non-bound peroxidase anti-TPA antibodies were removed by washing the bead. O-pheylenediamine was added to the bead as a substrate for peroxidase enzyme. The reaction was stopped after an appropriate incubation time. The intensity of the developed colour is proportional to TPS in the original serum sample.

\section{RESULTS}

Mean serum level TK and TPS showed significant increases from the corresponding levels for the normal healthy women and benign breast disease patients, (Table 1). Cutoff values of both markers were calculated as $\bar{x} \pm 2 S$.D. of the means for the non-cancer group (normal + benign disease, $\mathrm{n}=48$ ). It was $8 \mathrm{U} / \mathrm{L}$ for TK and $110 \mathrm{U} / \mathrm{L}$ for TPS. Sensitivity at that level was $47 \%$ for TK, $58 \%$ for TPS and $63 \%$ for combined markers.

Significant correlations were found between marker levels and certain prognostic factors, (table 2), but not with menstrual status, histological type and grade of tumour. 
Table 1. Serum TK and TPS in normal control, patients with benign mastopathies and breast cancer patients.

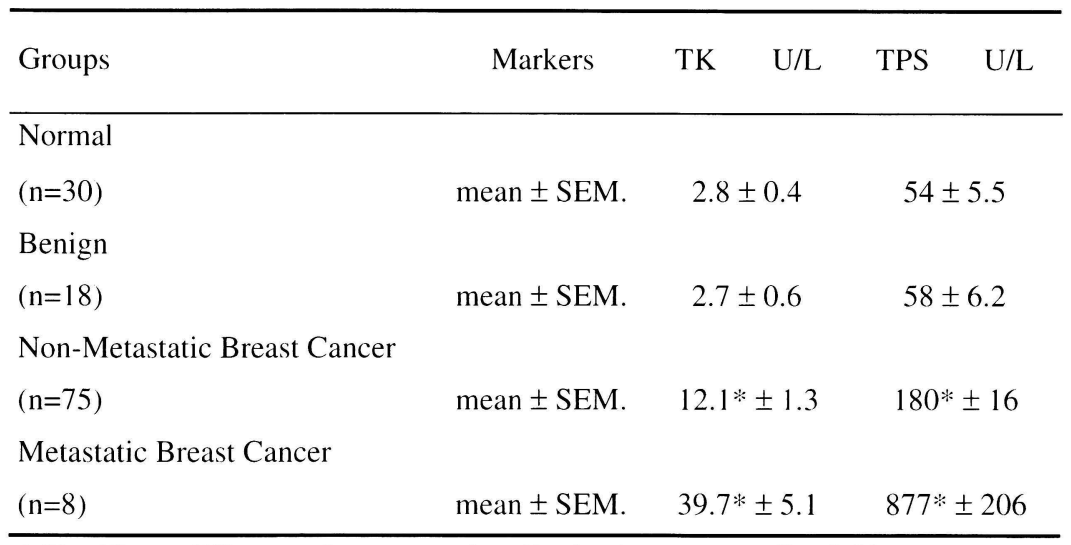

* Significant difference from normal and/or benign group at $\mathrm{P}<0.01$

Table 2. Serum TK and TPS in the different stages of breast cancer patients.

\begin{tabular}{|c|c|c|c|c|c|c|c|c|c|}
\hline & \multirow{2}{*}{$\begin{array}{l}\text { Prognostic } \\
\text { Factors }\end{array}$} & \multicolumn{2}{|c|}{$\begin{array}{l}\text { Clinical } \\
\text { stage }\end{array}$} & \multicolumn{2}{|c|}{$\begin{array}{l}\text { Tumor } \\
\text { size }\end{array}$} & \multicolumn{2}{|c|}{$\begin{array}{c}\text { Axillary } \\
\text { Lymph node }\end{array}$} & \multicolumn{2}{|c|}{$\begin{array}{c}\text { Distant } \\
\text { Metastasis }\end{array}$} \\
\hline Markers & & $\begin{array}{l}\mathrm{I}+\mathrm{II} \\
\mathrm{n}=33\end{array}$ & $\begin{array}{c}\text { III } \\
n=42\end{array}$ & $\begin{array}{l}\leq 2 \mathrm{~cm} \\
\mathrm{n}=15\end{array}$ & $\begin{array}{l}\geq 4 \mathrm{~cm} \\
\mathrm{n}=40\end{array}$ & $\begin{array}{l}N- \\
n=17\end{array}$ & $\begin{array}{c}\mathrm{N}+ \\
\mathrm{n}=58\end{array}$ & $\begin{array}{l}\text { MO } \\
n=75\end{array}$ & $\begin{array}{l}\text { M1 } \\
n=8\end{array}$ \\
\hline TK & mean & 8.3 & $15.2 *$ & 6.5 & $18.7 *$ & 6.1 & $17.2 *$ & 12.1 & $39.7 *$ \\
\hline $\mathrm{U} / \mathrm{L}$ & \pm SEM. & 0.8 & 1.4 & 0.8 & 1.7 & 0.7 & 1.6 & 1.3 & 5.1 \\
\hline TPS & mean & 86 & $233 *$ & 69 & $224 *$ & 82 & $311 *$ & 180 & $877 *$ \\
\hline $\mathrm{U} / \mathrm{L}$ & \pm SEM & 9 & 22 & 7 & 21 & 10 & 29 & 16 & 206 \\
\hline
\end{tabular}

* Significant difference from the corresponding stage at $\mathrm{P}<0.01$

Serum TK level reacted faster than TPS to radical mastectomy. Mean serum TK \pm S.E.M. level showed a significant decrease shortly after surgery $(7.7 \pm 1.0 \mathrm{U} / \mathrm{L})$, while a slight (insignificant) decrease of mean serum TPS level (156 $\pm 15 \mathrm{U} / \mathrm{L})$ was observed at this period (4-7 days).

Four months after radical mastectomy, two patients without evidence of metastasis showed dramatic increases in TPS level (>2000 U/l). Investigations confirmed viral hepatitis in both patients as the probable cause. 
Post-operatively the BC patients who were considered to be free of disease, showed a consistent decrease (see case 1) or fluctuation of TK and TPS levels below their cutoff values. A consistently raised TPS level above its reference range was show in chronic bilharzial women without evidence of breast cancer.

The BC patients who developed metastasis post-operatively $(n=7)$, showed an upward trend of both TK and TPS levels (6/7) with two months as the average lead-time (see case 2).

Bone metastasis was detected in case 3 one month after surgery. On applying Tamoxifen therapy both marker levels were normalized after two months with evident regression of disease. Case 4 was treated with CMF cytotoxic combination for 5 courses. During this period both markers remained above their reference range. Assessment of the patient showed progression of disease without any response to the treatment.

\section{DISCUSSION}

Serum TK and TPS were assayed separately in different studies to measure the proliferation rate of tumour and change in tumour burden. Their mean levels in BC patients showed a significant increase as compared to normal control or benign disease patients (Robertson et al., 1990; Oehr et al., 1992; Marino et al., 1992; Galloux et al., 1988; Spyratos et al 1992; McKenna et al., 1988). This finding is confirmed in the present work. Diagnostic sensitivities of TK and TPS were $47 \%$ and $58 \%$ respectively. The observed sensitivity of TPS , was very close to that obtained by Oehr et al. (1992) (51\%) and Marino et al. (1992) (47\%). It is obvious that these markers are too nonspecific to be considered as diagnostic tools for breast cancer. However, both parameters showed significant correlation with factors known to be valuable in prognosis such as clinical stage, pathological tumour size and number of invaded axillary lymph nodes. Gallaux et al. (1988) and Spyratos et al (1992) have found that TK activity is significantly related to the disease free survival in node negative $\mathrm{BC}$ patients. McKenna et al. (1988) have reported that pre-operative serum TK level can reflect the stage of breast cancer.

Van Dalen (1992) also have found a good correlation between serum TPS and stage of disease. In the present work, no correlation of either TK or TPS level to menstrual status, histological type and grade of tumour were observed.

Liu et al. (1992) have found no correlation between TPS stainability and histological grade of breast cancer.

Serum TK seems to react faster to radical mastectomy than TPS; the immediate postoperative level of the latter was not significantly changed from the pre-operative one. The short biological half life of TK (2.5 days) (Gronowitz and Küllander, 1984) may be responsible for this difference in response to radical mastectomy.

The present findings emphasize the close relationship between TPS level and liver function. TPS is excreted mainly through the biliary system and to lesser extent via the kidneys. This fact could explain the dramatic increase of TPS level in patients with acute viral hepatitis or chronic bilharziasis. Elevated TPS level was also found in steatosis hepatis, alcohol abuse, chronic and acute hepatitis (Bremer et al., 1992).

In the present work, serum TK and TPS levels showed a good sensitivity for detection of systemic metastasis in six out of seven patients $(85 \%)$ with average lead-time 2 months before clinical diagnosis. Other investigators have found $90 \%$ sensitivity for 

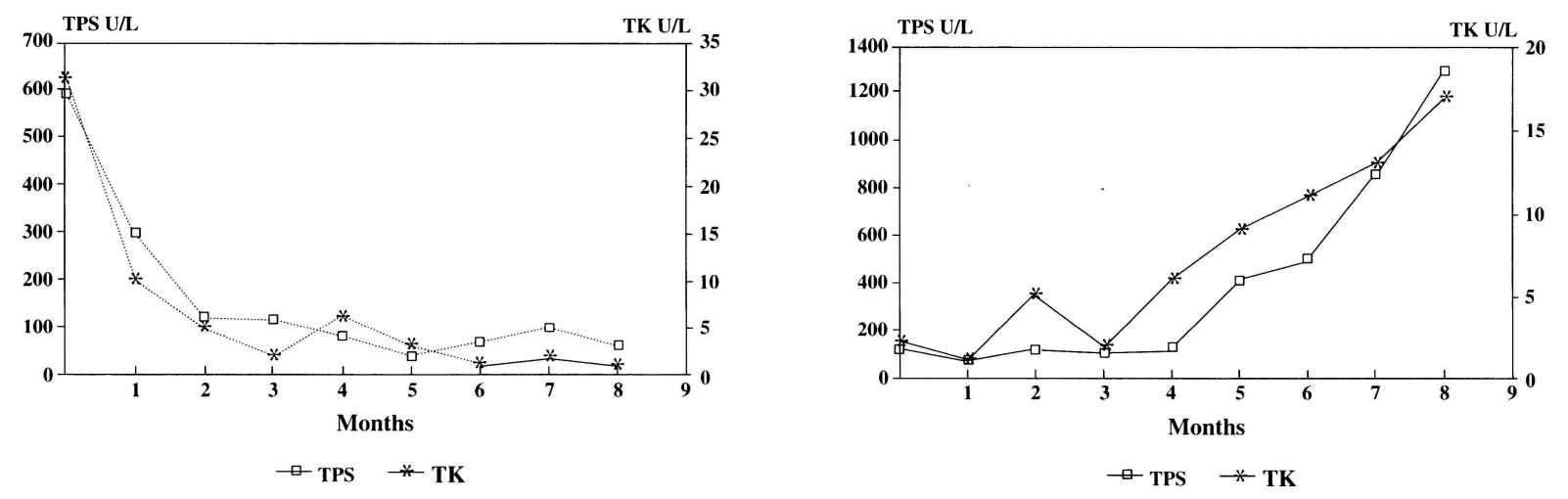

Case №. 2
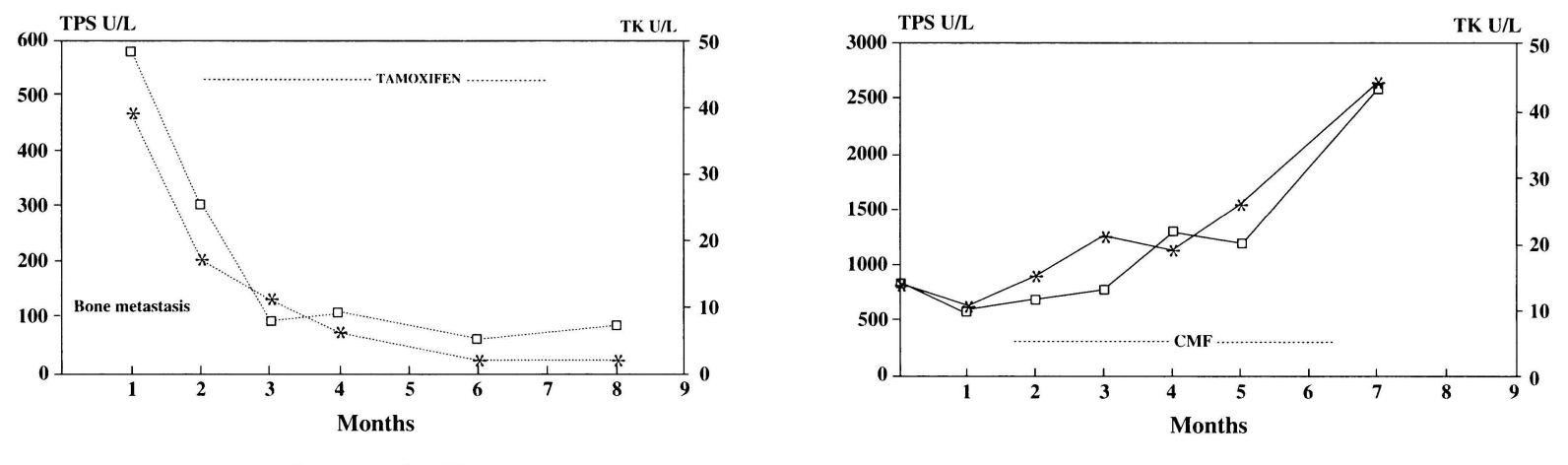

${ }_{-T}$ TPS $\quad$ - TK 
TPS (Van Dalen, 1992) and 100\% for TK (Robertson et al., (1990) in detecting metastatic spread.

In the present findings, both serum markers showed significant changes parallel to regression or progression of disease on therapy. These results have confirmed the findings of other workers about the role of TPS and TK in therapeutic monitoring (Bremer et al., 1992; Robertson et al., 1990; Marino et al., 1992).

In conclusion, serum TK and TPS have low diagnostic sensitivity for primary breast cancer. However, their serial determination after mastectomy can detect systemic recurrence. Preoperative serum TK and TPS levels may have prognostic value. Both markers could be used in assessment of therapeutic efficacy. Finally, the presence of liver disease should be considered when interpreting TPS level.

\section{REFERENCES}

Bello, L.J. (1974). Regulation of thymidine kinase synthesis in human cell. Exp. Cell Res., 89, 263. Bjorklund, B., Bjorklund, V. (1983). Specificity and basis of the TPA. Cancer Det. and Prev., 6, 41.

Bremer, K., Richter, K., Bremer, G., Kibing, F. (1992). Clinical value of TPS in breast cancer patient. In: Klapdor, R. (Ed.), Tumor associated antigen, oncogenes, receptors, cytokines in tumor diagnosis and therapy at the beginning of the nineties. München, Bern. W. Zuckschwerdt Verlag, 1992, pp. 52.

Galloux, H., Javre, J., Guerin, D., Samperez, S., Jouan, P. (1988). Prognostic value of fetal TK measurement in breast cancer., C.R. Acad. Sci. III, 306(3), 89.

Gronowitz, J., Küllander, C. (1984). Extra cellular expression of TK isoenzyme in human body fluids, with special reference to herpes virus diagnostic and use for monitoring antiviral therapy. In: Sanna, A., Morace, G. (Eds.), New Horizon in Microbiology. Elsevier Science Publishing BV, Amsterdam, 1984, pp. 273.

Gronowitz, J.S., Källander, C.F., Diderholm, H., Hagberg, H., Pettersson, U. (1984). Application of an in vitro assay for serum TK: results on viral disease and malignancies in humans. Int. J. Cancer, 33, 5.

Hallek, H., Wander, L., Stromeyer, S., Emmerich, B. (1992). Thymidine kinase: a tumor marker with prognostic value for non-Hodgkin's lymphoma and a broad range of potential clinical application. Ann. Haematol., 65, 1.

Hagberg, H., Glimelius, B., Gronowitz, S., Killander, A., Källander, C., Schröder, T. (1984). Biochemical markers in non-Hodgkin's lymphoma stage III and IV and prognosis: A multivariate analysis. Scand. J. Haematol., 33, 59.

Liu, Q., Nap, M., Oehr, P. (1992). The immunohistochemical relation between TPS, Ki67 and proliferation. In: Klapdor, R. (Ed.), Tumorassociated antigens, oncogenes, receptors, cytokines in tumor diagnosis. München, Bern, Zuckschwerdt Verlag, 1992, pp.214.

Madersbacher, S., Gregor, N., Theyer, G., Steiner, G., Marberger, M. (1992). TPS is useful epithelial proliferation and tumor marker. Amer. Urol. Ass. Annual Meeting, Washington, 1992.

Marino, P., Buccher, G., Preatoni, A., Ferrigno, D., Luporini, A.C., Pravettoni, G. (1992). Tissue polypeptide specific antigen (TPS) and objective response to treatment is solid tumors. Int. $J$. Biological Markers, 7(1), 56.

McKenna, P., O'Neill, K., Abram, W., Hannigen, B.(1988). Thymidine kinase activities in mononuclear leucocytes and serum from breast cancer patients. Br. J. Cancer, 57(6), 619.

Oehr, P. (1992). TPS, TPA and keratins: Similarities and difference (meeting abstract). The 9th International Conference on Human Tumor Markers, Vienna, Austria, Sept. 6-9, 1992. 
Oehr, P., Liu, Q., Jin, H.Y., Halim, A-B., El-Ahmadyu, O., Nap, M., Lackner, Schultes, B., Ota, Y. (1992). TPS: Biological and clinical value. In: Klapdor, R. (Ed.), Tumor associated antigens, oncogenes, receptors, cytokines in tumor diagnosis and therapy at the beginning of the nineties. München, Bern. W. Zuckschwerdt Verlag, 1992, pp.213.

Robertson, J., O’Neill, K., Thomas, M., Mckenna, P., Blamey, R. (1990). Thymidine kinase in breast cancer. Br. J. Cancer, 62(4), 663.

Spyratos, F., Martin, P., Hacen, K. et al. (1992). Multiparametric Prognostic evaluation of biological factor in primary breast cancer. J. Natl. Cancer Inst., 84(16), 1266.

Van Dalen, A. (1992). TPS in breast cancer - A comparative study with carcinoembryonic antigen and CA 15-3. Tumor Biol., 13, 10.

Van Dalen, A. Is TPS able to assist in decision making in breast cancer? In: Klapdor, R. (Ed.), Tumor associated antigens, oncogenes, receptors, cytokines in tumor diagnosis and therapy at the beginning of the nineties. München, Bern, Zuckschwerdt Verlag, 1992, pp.86. 


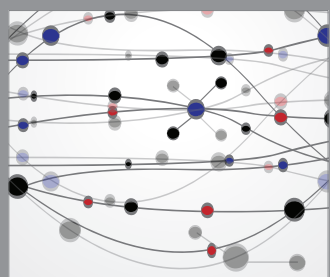

The Scientific World Journal
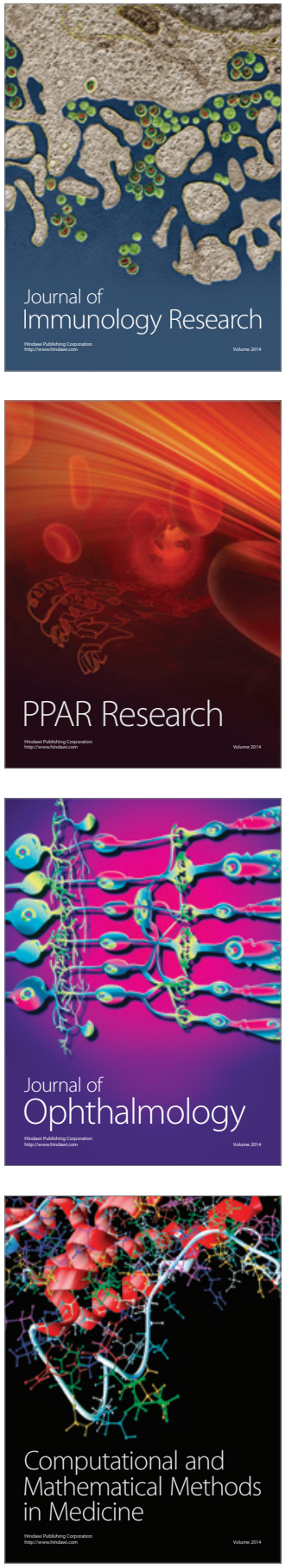

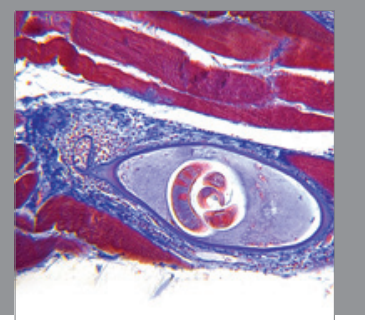

Gastroenterology

Research and Practice
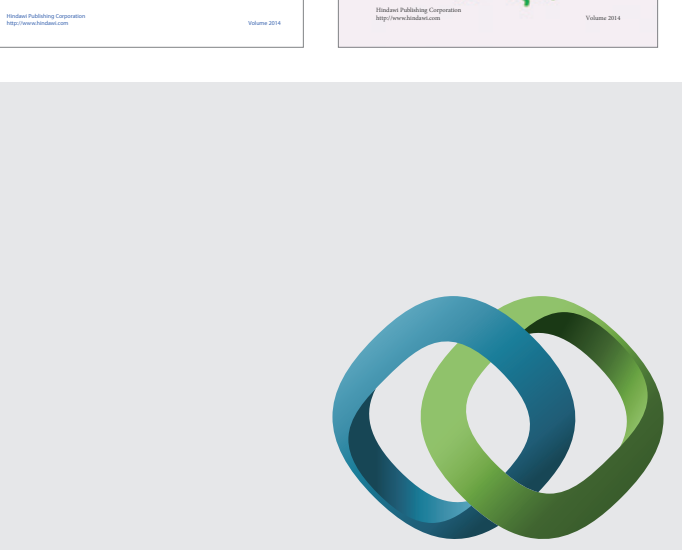

\section{Hindawi}

Submit your manuscripts at

http://www.hindawi.com
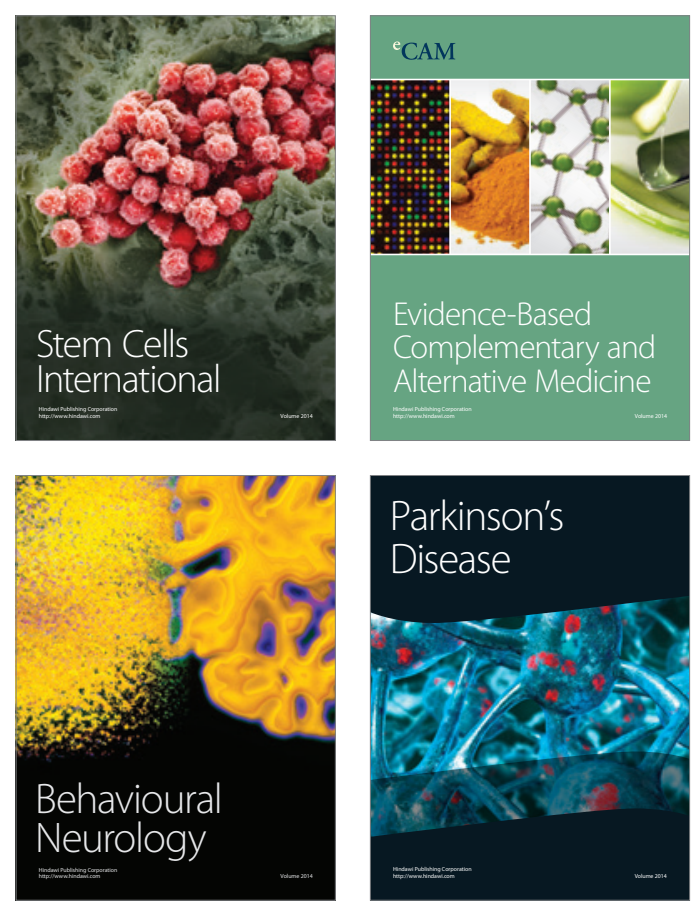

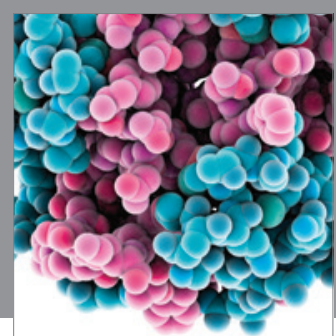

Journal of
Diabetes Research

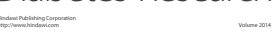

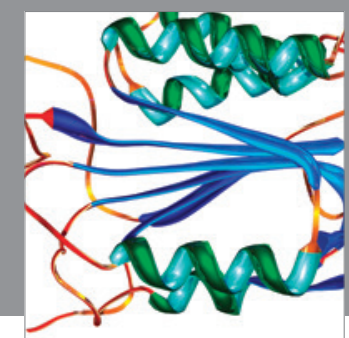

Disease Markers
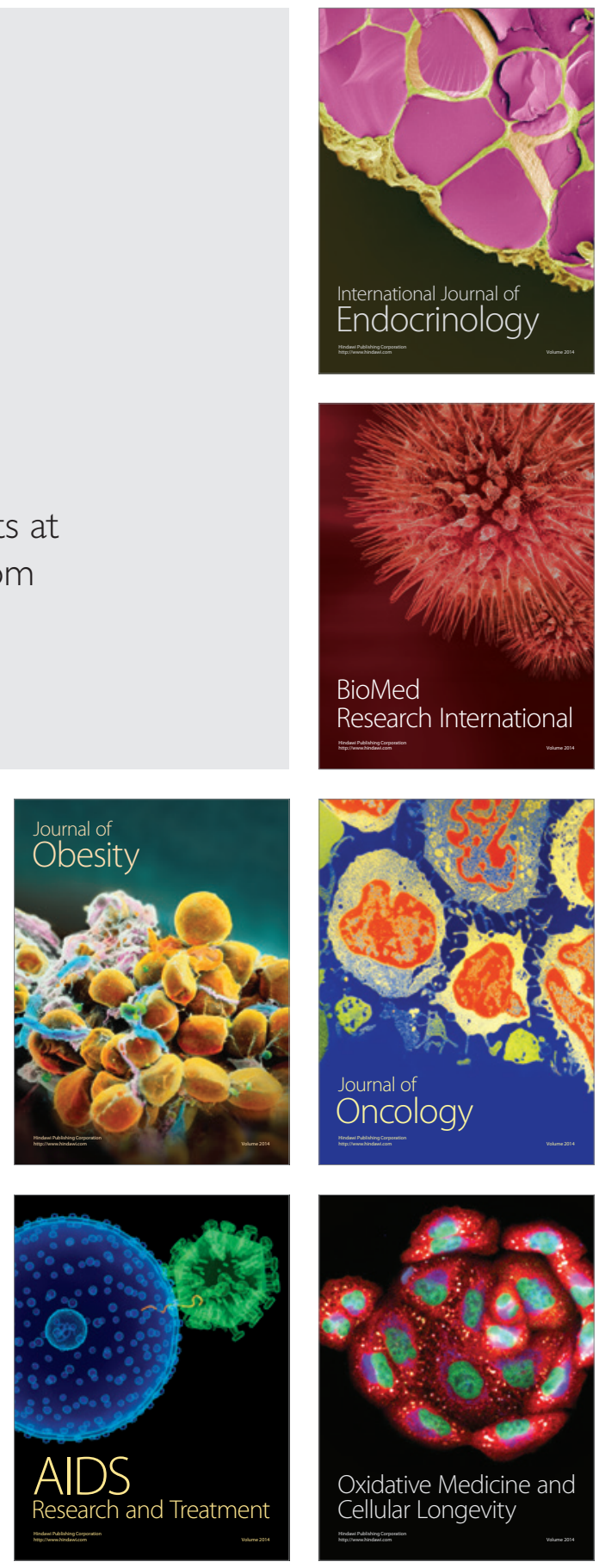